\title{
ARTICLES
}

\section{Apolipoprotein E Phenotype Regulates Cholesterol Absorption in Healthy 13-Month-Old Children-The STRIP Study}

\author{
ANNE TAMMI, TAPANI RÖNNEMAA, LEENA RASK-NISSILÄ, TATU A. MIETTINEN, \\ HELENA GYLLING, LIISA VALSTA, JORMA VIIKARI, ILKKA VÄLIMÄKI, AND OLLI SIMELL \\ Research Centre of Applied and Preventive Cardiovascular Medicine, University of Turku, \\ Kiinamyllynkatu 10, FIN-20520 Turku, Finland [A.T., L.R-N.]; Department of Medicine, University of \\ Turku, Kiinamyllynkatu 4-8, FIN-20520 Turku, Finland [T.R., J.V.]; Department of Medicine, University \\ of Helsinki, P.B. 342, FIN-00029 Helsinki University Central Hospital, Finland [T.A.M., H.G.]; National \\ Public Health Institute, Mannerheimintie 166, FIN-00300 Helsinki, Finland [L.V.]; Department of \\ Pediatrics, University of Turku, Kiinamyllynkatu 4-8, FIN-20520 Turku, Finland [A.T., L.R-N., I.V., O.S.].
}

\begin{abstract}
High serum cholesterol concentration is one of the key risk factors in development of atherosclerosis, which may begin early in life and later progress to symptomatic coronary heart disease. In adults, apoE polymorphism strongly influences cholesterol metabolism, as subjects with apoE $3 / 4$ or $4 / 4$ (collectively called apoE4) phenotype absorb cholesterol effectively and thus also have higher cholesterol absorption-reflecting plant sterol concentrations in serum than subjects with other apoE phenotypes. Because of the inverse correlation of absorption and synthesis of cholesterol, concentrations of cholesterol synthesis-reflecting serum cholesterol precursor sterols are lower in subjects with apoE4 than in subjects with other phenotypes. To analyze whether apoE phenotype affects cholesterol absorption and synthesis in early childhood, we measured serum plant sterol (campesterol and sitosterol) and cholesterol precursor sterol (desmosterol and lathosterol) concentrations in healthy 13-month old children using gas-liquid chromatography. The 36 study children
\end{abstract}

\section{ABSTRACT}

were participants in a randomized prospective trial (the Special Turku Coronary Risk Factor Intervention Project) aimed at decreasing exposure of the children to environmental atherosclerosis risk factors. The 16 apoE4 children had $30 \%$ to $50 \%$ higher cholesterol-adjusted campesterol and sitosterol concentrations in serum than the $20 \mathrm{apoE} 3 / 3$ children $(p=0.002$ and $p=0.02$, respectively). The concentrations of cholesterol precursor sterols in serum did not differ between the two groups of children. We conclude that the young apoE4 children may absorb cholesterol and plant sterols more effectively than the children with apoE $3 / 3$ phenotype without compensatory reduction in endogenous synthesis of cholesterol. (Pediatr Res 50: 688-691, 2001)

Abbreviations
E\%, percent of daily total energy intake
non-HDL cholesterol, total cholesterol - HDL cholesterol

Plant sterols, components of vegetal cellular membranes, are structurally closely related to cholesterol. Only small amounts of poorly absorbed plant sterols are found in human plasma or serum $(1,2)$, and they are entirely derived from the diet, since they are not synthesized endogenously (1). In middle-aged

Received November 8, 2000; accepted June 18, 2001.

Correspondence and reprint requests to: Anne Tammi, Research Centre of Applied and Preventive Cardiovascular Medicine, University of Turku, Kiinamyllynkatu 10, FIN20520 Turku, Finland; e-mail: anne.tammi@utu.fi

Supported by grants from Foundation for Pediatric Research, Finland, Medical Council of the Academy of Finland, Sigrid Juselius Foundation, Yrjö Jahnsson Foundation, Finnish Cardiac Research Foundation, Juho Vainio Foundation, Turku University Foundation, and Turku University Hospital Research Fund. subjects, serum cholesterol-adjusted plant sterol concentrations reflect cholesterol absorption $(2,3)$. Subjects with apoE 3/4 or 4/4 phenotype absorb cholesterol more effectively (4), and have thus higher serum plant sterol concentrations than subjects with other apoE phenotypes (5).

In addition to cholesterol and plant sterols, plasma also contains cholesterol precursor sterols, e.g. lathosterol and desmosterol, which reflect the activity of endogenous cholesterol synthesis $(2,6)$. Because the rate of cholesterol synthesis is lower in subjects with apoE $3 / 4$ or $4 / 4$ phenotypes than in those with other phenotypes (7), serum lathosterol concentrations are lower in subjects with apoE 3/4 or $4 / 4$ phenotype than in subjects with other apoE phenotypes 
(4). As cholesterol absorption and synthesis are inversely correlated with each other (8), serum concentrations of plant sterols and cholesterol precursor sterols are also inversely correlated in healthy men (9) and in patients with familial hypercholesterolemia (10).

Because a high serum cholesterol concentration is one of the most important risk factors in development of atherosclerosis (11), factors regulating serum cholesterol concentration since birth are important in planning of proper strategies for the prevention of atherosclerosis development. We studied extent to which apoE phenotype regulates cholesterol absorption and synthesis in early childhood by determining serum plant sterol and cholesterol precursor sterol concentrations in 36 children (16 with apoE $3 / 4$ or $4 / 4$ phenotype; 20 with apoE $3 / 3$ phenotype) at the age of 13 months.

\section{METHODS}

Subjects. The children in this study were all 13-month-old participants of the STRIP project (Special Turku Coronary Risk Factor Intervention Project for children), which is a randomized, prospective trial aimed at decreasing exposure of the intervention children to known environmental atherosclerosis risk factors. In the project, launched in 1990, 1062 infants were randomized to the intervention $(n=540)$ or control $(n=$ 522) group at the age of 7 months as described (12). The children in the intervention group received dietary counseling aiming at low intake of saturated fat and cholesterol at regular intervals. We recommended that the intervention families add 2-3 teaspoonfuls of vegetable oil (preferably low-erucic acid rapeseed oil) or vegetable margarine to the child's daily diet to replace the saturated fat. Not only cholesterol absorption rate, but also the amount of plant sterols in the diet may affect serum plant sterol concentrations (13). The main dietary sources of plant sterols in western diets are vegetable oils and margarines (14). To confirm equal dietary intake of plant sterols, we selected for the present study only intervention children from STRIP. We randomly selected thirty-seven 13-month-old in- tervention children, who, according to 3-day dietary records, fulfilled the criteria of recommended vegetable oil or margarine intake (Table 1). Seventeen of the children had the apoE $3 / 4$ or $4 / 4$ phenotype (later called children with apoE4 phenotype), while the remaining 20 children had the apoE 3/3 phenotype. One boy with the apoE 3/4 phenotype was excluded from analyses because he had an extremely low serum cholesterol concentration $(1.70 \mathrm{mmol} / \mathrm{L})$ caused by asymptomatic hypobetalipoproteinemia. The mean (SD) daily vegetable fat supplement of the apoE4 children was 13.4 (5.6) g, and that of the apoE 3/3 children 12.5 (5.6) $\mathrm{g}(p=0.62)$.

Counseling. The intervention families visited the study pediatrician and dietitian at the child's age of $7,8,10$, and 13-months old. The families were advised to feed the children low-saturated fat, low-cholesterol diets, which after discontinuation of breast milk or formula at the age of 12 months contained, for example, skim milk; therefore, the children's daily diets were supplemented with 2-3 teaspoonfuls of vegetable oil or margarine. The suggested total fat intake of the children was $30 \%$ to $35 \%$ of their daily E \%. The counseling dealt mainly with quality of fat in child's diet, aimed at replacing part of saturated fatty acids with poly- and monounsaturated fatty acids to approach a polyunsaturated/monounsaturated/saturated fatty acid ratio of 1/1/1 and a daily cholesterol intake $<200 \mathrm{mg}$. Control families visited the project pediatrician and dietitian at child's ages of 7 and 13 months old. They were counseled like families at the Finnish well-baby clinics to change the child from breast milk or formula to cow's milk with $1.9 \%$ or $2.9 \%$ fat at the age of one year, and they received no individualized dietary advice. The intervention and control families recorded child's food consumption for 3 days (one weekend day) about a week before each visit using a food diary. The intake data were analyzed using Micro-Nutrica ${ }^{\circledR}$ program (Research and Development Unit, Social Insurance Institution, Turku, Finland) (15). Daily intake of plant sterols was estimated using a database developed in the National Public Health Institute and added to the Micro-Nutrica ${ }^{\circledR}$ pro-

Table 1. Characteristics of the study subjects and their daily intake of energy and fat according to 3-day dietary record in children with apoE $3 / 3(n=20)$ and apoE $3 / 4$ or apoE $4 / 4$ phenotype $(n=16)$

\begin{tabular}{|c|c|c|c|}
\hline Variable & Children with apoE $3 / 3$ & Children with apoE $3 / 4$ or apoE $4 / 4$ & $p$-value \\
\hline Female, $n$ & 6 & 8 & \\
\hline Male, $n$ & 14 & 8 & \\
\hline Height, $\mathrm{cm}$ & $78.3(2.7)$ & $77.5(2.1)$ & 0.34 \\
\hline Relative weight, $\% *$ & $+0.5(10.4)$ & $+1.0(7.6)$ & 0.87 \\
\hline \multicolumn{4}{|l|}{ Dietary intakes } \\
\hline Total energy, $\mathrm{MJ} \dagger$ & $4.43(0.85)$ & $4.12(0.77)$ & 0.29 \\
\hline Monounsaturated fat, E\% & $9.9(2.5)$ & $12.1(1.9)$ & 0.006 \\
\hline Polyunsaturated fat, E\% & $6.4(2.4)$ & $7.2(1.6)$ & 0.31 \\
\hline $\mathrm{P} / \mathrm{S}$ ratiot & $0.88(0.27)$ & $0.92(0.34)$ & 0.67 \\
\hline Cholesterol, mg & $82(33)$ & $85(47)$ & 0.85 \\
\hline Plant sterols, mg & $168(53)$ & $182(51)$ & 0.42 \\
\hline
\end{tabular}

Values are means (SD).

* Relative weight expresses weight as deviation from mean weight of Finnish children of same height and sex.

$\uparrow$ To convert MJ to kcal multiply by 239 .

$\ddagger \mathrm{P} / \mathrm{S}$, ratio of polyunsaturated fatty acids to saturated fatty acids. 
Table 2. Concentrations of serum lipids (mmol/l) in children with apoE $3 / 3$ phenotype $(n=20)$ and with apoE $3 / 4$ or apoE $4 / 4$ phenotype

\begin{tabular}{lccc} 
& & & \\
\multicolumn{1}{c}{ Variable } & Children with apoE $3 / 3$ & Children with apoE $3 / 4$ or $4 / 4$ & $p$-value \\
\hline Total cholesterol & $3.78(0.61)$ & $4.00(0.57)$ & 0.28 \\
HDL cholesterol & $0.84(0.19)$ & $0.82(0.19)$ & 0.81 \\
HDL cholesterol/total cholesterol & $0.23(0.05)$ & $0.20(0.04)$ & 0.20 \\
Non-HDL cholesterol & $2.94(0.60)$ & $3.18(0.46)$ & 0.21
\end{tabular}

Values are means (SD).

gram. Sterol values of foods analyzed chemically ranged from $70 \%$ to $98 \%$ of the calculated sterol values (16).

Biochemical determinations. Blood was drawn from an antecubital vein under cutaneous anesthesia (Emla, Astra, Södertälje, Sweden) from nonfasting children at the age of 13 months. Serum was separated by centrifugation $(3400 \times g$, for 12 minutes) after clotting at room temperature and was stored at $-25^{\circ} \mathrm{C}$ for less than one month. Serum cholesterol concentration and HDL cholesterol concentration after precipitation of LDL and VLDL with dextran sulfate 500,000 were measured using a fully enzymatic method. Samples for the measurement of serum concentrations of cholesterol, plant sterols, and cholesterol precursor sterols were stored at $-70^{\circ} \mathrm{C}$ until determined with gas liquid chromatography $(17,18)$ at the Research Laboratory of the Department of Medicine, Helsinki University Central Hospital, using $50 \mathrm{~m}$ capillary SE-30 column (Hewlett Packard ${ }^{\circledR}$ Ultra I). ApoE phenotypes were determined using isoelectric focusing and immunoblotting of delipidated serum (19).

Statistical analysis. The results are expressed as means (SD). For statistical analysis the SAS 6.12 program package was used (SAS Institute, Cary, NC). Two-sided $p$-values $<0.05$ were regarded as significant. Differences between the apoE4 children and the apoE $3 / 3$ children were tested with a two-sample $t$ test. Pearson correlation coefficient was calculated for correlation between variables.

Ethics. The Joint Commission on Ethics of the Turku University and the Turku University Central Hospital have approved STRIP. An informed consent was obtained from the parents of all children.

\section{RESULTS}

The measured serum lipid concentrations (cholesterol, HDL cholesterol, HDL cholesterol/cholesterol, and non-HDL cho- lesterol) did not differ significantly between the 16 children with apoE4 and the 20 children with apoE $3 / 3$ (Table 2).

Serum concentrations of campesterol and sitosterol were $54 \%$ and $35 \%$ higher, respectively, in the apoE4 children than in the apoE 3/3 children (Table 3). When the concentrations of campesterol and sitosterol were adjusted for serum cholesterol, the values in the apoE4 children exceeded those of the apoE $3 / 3$ children by $45 \%$ and $27 \%$, respectively. However, serum concentrations of cholesterol precursor sterols or their cholesterol-adjusted concentrations did not differ between the two groups of children (Table 3).

Plant sterol concentrations in serum showed no correlation with cholesterol precursor sterols in the two groups of children studied either separately or combined (data not shown).

\section{DISCUSSION}

This study shows that the children with apoE4 phenotype have higher serum concentrations of plant sterols in early childhood than the children with apoE $3 / 3$ phenotype. This finding may reflect higher absorption of dietary cholesterol in the apoE4 children than in the apoE 3/3 children. However, contrary to findings in adults, the children with the two phenotypes had similar cholesterol precursor concentrations. Consequently, the concentrations of serum plant sterols and cholesterol precursor sterols did not correlate with each other in these children.

Adult subjects with apoE4 absorb cholesterol more effectively than others, thus showing high cholesterol-adjusted serum plant sterol concentrations $(4,5)$. Similarly, in this study, the young children with apoE4 phenotype had higher cholesterol-adjusted serum campesterol and sitosterol concentrations than the children with the apoE $3 / 3$ phenotype, even though dietary plant sterol intakes of children in the two groups did not

Table 3. Serum concentrations of non-cholesterol sterols $\left(10^{2} \mu \mathrm{mol} / \mathrm{l}\right)$ and sterol to cholesterol ratio $\left(10^{2} \mu \mathrm{mol} / \mathrm{l}\right.$ of cholesterol) in children with apolipoprotein (apo) E3/3 $(n=20)$ and apo E3/4 or apo E4/4 phenotype $(n=16)$

\begin{tabular}{|c|c|c|c|}
\hline Sterol & Children with apoE $3 / 3$ & Children with apoE $3 / 4$ or apoE $4 / 4$ & $p$-value \\
\hline \multicolumn{4}{|c|}{ Sterols reflecting cholesterol absorption } \\
\hline Campesterol & $737(290)$ & $1137(375)$ & 0.0009 \\
\hline Campesterol/cholesterol & $205(81)$ & $297(80)$ & 0.002 \\
\hline Sitosterol/cholesterol & $140(38)$ & $178(52)$ & 0.02 \\
\hline \multicolumn{4}{|c|}{ Sterols reflecting cholesterol synthesis } \\
\hline Desmosterol & $284(59)$ & $298(70)$ & 0.53 \\
\hline Lathosterol/cholesterol & $132(42)$ & $123(32)$ & 0.51 \\
\hline
\end{tabular}

Values are means (SD). 
differ. The dietary intakes of total and monounsaturated fat were higher in the apoE4 children than in the apoE 3/3 children. On the other hand, no correlations were detected between these dietary intakes and the cholesterol-adjusted serum concentrations of campesterol or sitosterol in either group of children ( $\mathrm{r}$ always $<0.35, p$ always $>0.13$ ). Therefore, it is unlikely that the increased cholesterol absorption efficiency (reflected by plant sterol levels) in the apoE4 children would be caused by their higher dietary intake of total and monounsaturated fat (7). Our findings also support the hypothesis that increased cholesterol absorption is a mechanism by which the apoE4 phenotype influences serum cholesterol concentrations in childhood as has been previously demonstrated (19-22). Also, in the present study, there was a tendency toward higher serum total cholesterol concentrations in the apoE4 children, although the difference was not significant, probably owing to the small number of study subjects (36 children). In fact, a similar difference in serum cholesterol concentration $(0.22 \mathrm{mmol} / \mathrm{l})$ between apoE4+ and apoE4children was significant $(p=0.0001)$ in the original STRIP with 723 children (23).

In adults serum cholesterol-adjusted concentrations of plant sterols and cholesterol precursor sterols are inversely correlated with each other, reflecting an inverse correlation with cholesterol absorption and synthesis $(9,10)$. However, in this study, the 13-month-old children did not show any correlation between serum cholesterol-adjusted plant sterol and cholesterol precursor sterol concentrations. Further, the children with the apoE4 phenotype and those with the apoE $3 / 3$ phenotype showed no difference in serum absolute or cholesterol-adjusted precursor sterol concentrations, even though cholesterol absorption, as reflected by serum plant sterols, was higher in the children with the apoE4 phenotype compared with the children with the apoE $3 / 3$ phenotype. Because the daily intake of cholesterol was less than $90 \mathrm{mg}$ in both groups of children and thus far below the common intake values of adults (24), the low intake and small amount of cholesterol absorbed might not suppress cholesterol synthesis to such an extent that changes in the precursor concentrations would become visible (24-26). Such a phenomenon may occur especially in children below the age of 2 years, because the growth velocity of the children is still extremely fast, and high rates of endogenous cholesterol synthesis are needed for construction of the new cell membranes and other membranous structures in the cells.

In summary, this study shows that the healthy children with apoE4 phenotype had higher absolute and cholesterol-adjusted concentrations of plant sterols in serum than the children with the apoE $3 / 3$ phenotype at the age of 13 months, but both absolute and cholesterol-adjusted concentrations in serum of sterols reflecting cholesterol synthesis did not differ between the two phenotypes. These findings suggests that the apoE4 children absorb cholesterol more effectively than the children with apoE $3 / 3$ phenotype, but the increased absorption of cholesterol was not accompanied by a compensatory reduction in cholesterol synthesis.

\section{REFERENCES}

1. Salen G, Ahrens Jr. EH, Grundy SM 1970 Metabolism of $\beta$-sitosterol in man. J Clin Invest 49:952-967

2. Miettinen TA, Tilvis RS, Kesäniemi YA 1990 Serum plant sterols and cholesterol precursors reflect cholesterol absorption and synthesis in volunteers of a randomly selected male population. Am J Epidemiol 131:20-31

3. Tilvis RS, Miettinen TA 1986 Serum plant sterols and their relation to cholesterol absorption. Am J Clin Nutr 43:92-97

4. Kesäniemi YA, Ehnholm C, Miettinen TA 1987 Intestinal cholesterol absorption efficiency in man is related to apoprotein E phenotype. J Clin Invest 80:578-581

5. Uusitupa MI, Miettinen TA, Sarkkinen ES, Ruuskanen E, Kervinen K, Kesäniemi YA 1997 Lathosterol and other non-cholesterol sterols during treatment of hypercholesterolemia with beta-glucan rich oat bran. Eur J Clin Nutr 51:607-611

6. Kempen HJM, Glatz JFC, Gevers Leuven JA, van der Voort HA, Katan MB 1988 Serum lathosterol is an indicator of whole-body cholesterol synthesis in humans. J Lipid Res 29:1149-1156

7. Miettinen TA, Gylling H, Vanhanen H, Ollus A 1992 Cholesterol absorption, fecal elimination, and synthesis related to LDL kinetics during varying fat intake in men with different apoprotein E phenotypes. Arterioscler Thromb 12:1044-1052

8. Grundy SM, Ahrens, Jr. EH, Davignon J 1969 The interaction of cholesterol absorption and cholesterol synthesis in man. J Lipid Res 10:304-315

9. Sutherland WHF, Robertson MC, Williamson SA, Nye ER 1991 Plasma noncholesterol sterols in male distance runners and sedentary men. Eur J Appl Physiol 63:119-123

10. Gylling H, Miettinen TA 1988 Serum noncholesterol sterols related to cholesterol metabolism in familial hypercholesterolemia. Clin Chim Acta 178:41-50

11. Kannel WB, Castelli WP, Gordon T 1979 Cholesterol in the prediction of atherosclerotic disease. New perspective on the Framingham study. Ann Intern Med 90:85-91

12. Lapinleimu H, Viikari J, Jokinen E, Salo P, Routi T, Leino A, Rönnemaa T, Seppänen R, Välimäki I, Simell O 1995 Prospective randomized trial in 1062 infants of diet low in saturated fat and cholesterol. Lancet 345:471-476

13. Vanhanen HT, Miettinen TA 1992 Effects of unsaturated and saturated dietary plant sterols on their serum contents. Clin Chim Acta 97-107

14. Weihrauch JL, Gardner JL 1978 Sterol content of foods of plant origin. J Am Diet Assoc 73:39-47

15. Hakala P, Marniemi J, Knuts L-R, Kumpulainen J, Tahvonen R, Plaami S 1996 Calculated vs analysed nutrient composition of weight reduction diets. Food Chem 57:71-75

16. Heinonen M, Valsta L, Anttolainen M, Ovaskainen M-L, Hyvönen L, Mutanen M 1997 Comparisons between analyzed and calculated food composition data: carotenoids, retinoids, tocopherols, tocotrienols, fat, fatty acids, and sterols. J Food Comp Anal 10:3-13

17. Miettinen TA, Koivisto P 1983 Non-cholesterol sterols and bile acid production in hypercholesterolaemic patients with ileal bypass. In: Paumgartner G, Stiehl A, Gerok W, (eds) Bile acids and cholesterol in health and disease. MTP Press, Lancaster, England, pp 183-187

18. Miettinen TA 1988 Cholesterol metabolism during ketokonazole treatment in man J Lipid Res 29:43-51

19. Lehtimäki T, Moilanen T, Viikari J, Åkerblom HK, Ehnholm C, Rönnemaa T, Marniemi J, Dahlen G, Nikkari T 1990 Apolipoprotein E phenotypes in Finnish youths: a cross-sectional and 6-year follow-up study. J Lipid Res 31:487-495

20. Lapinleimu H, Viikari J, Rönnemaa T, Välimäki I, Tuominen J, Marniemi J, Ehnholm C, Jokinen E, Simell O 1996 Apolipoprotein E polymorphism and serum lipids in a randomized prospective trial of an infant diet with reduced saturated fat and cholesterol. Pediatrics 98:757-762

21. Srinivasan SR, Ehnholm C, Wattigney WA, Bao W, Berenson GS 1996 The relation of apolipoprotein $\mathrm{E}$ polymorphism to multiple cardiovascular risk in children: the Bogalusa Heart Study. Atherosclerosis 123:33-42

22. Kallio MJ, Salmenperä L, Siimes MA, Gylling H, Miettinen TA 1997 Apoprotein E determines serum cholesterol in infants during both high-cholesterol breast feeding and low-cholesterol formula feeding. J Lipid Res 38:759-764

23. Tammi A, Rönnemaa T, Viikari J, Jokinen E, Lapinleimu H, Ehnholm C, Simell O 2000 Apolipoprotein E4 phenotype increases non-fasting serum triglyceride concentration in infants-the STRIP Study. Atherosclerosis 152:135-141

24. Miettinen TA, Kesäniemi YA 1989 Cholesterol absorption: regulation of cholesterol synthesis and elimination and within-population variations of serum cholesterol levels. Am J Clin Nutr 49:629-635

25. Lin DS, Connor WE 1980 The long term effects of dietary cholesterol upon the plasma lipids, lipoproteins, cholesterol absorption and sterol balance in man: the demonstration of feedback inhibition of cholesterol biosynthesis and increased bile acid synthesis. J Lipid Res 21:1042-1052

26. Cruz MLA, Wong WW, Mimouni F, Hachey DL, Setchell KDR, Klein PD, Tsang RC 1994 Effects of infant nutrition on cholesterol synthesis rate. Pediatr Res $35: 135-140$ 